\title{
Parasitic loads in torque standard machines: a characterisation, comparison, and evaluation
}

\author{
Sebastian Baumgarten¹, Dirk Röske1, Jussi Ala Hiiro², Lukáš Vavrečka³, Stefan Kock ${ }^{4}$ Jonas Gnauert ${ }^{4}$ \\ 1 Physikalisch-Technische Bundesanstalt, Bundesallee 100, 38116 Braunschweig, Germany \\ 2 Teknologian tutkimuskeskus VTT Oy (VTT), Centre for Metrology MIKES Force Metrology, Tehdaskatu 15, Puristamo 9P19, FI 87100 \\ Kajaani, Finland \\ ${ }_{3}^{3}$ Cesky Metrologicky Institut Brno (CMI), Department of force and torque, V Botanice 1504/4, 15072 Praha, Czech Republic \\ ${ }^{4}$ RWTH Aachen, Chair for Wind Power Drives, Campus-Boulevard 61, 52074 Aachen, Germany
}

\begin{abstract}
In torque standard machines, different kinds of bearings are used to reduce the influence of parasitic loads under the assumption that such loads are low. In accordance with EURAMET cg-14, the signal of a torque transducer is averaged over three mounting positions. For this reason, the influence of parasitic loads on the transducer signal should be negligible. To test this assumption, two multicomponent torque transducers are characterised in this study based on experimental, analytical, and numerical results. In this article, the parasitic loads of the torque standard machines at the Physikalisch-Technische Bundesanstalt (PTB), Teknologian tutkimuskeskus VTT Oy (VTT), and Cesky Metrologicky Institut (CMI) were characterised and compared. The results are presented together with a proposal for an evaluation.
\end{abstract}

\section{Section: RESEARCH PAPER}

Keywords: torque, torque standard machine, parasitic load, comparison, multi-component, crosstalk

Citation: Sebastian Baumgarten, Dirk Röske, Jussi Ala Hiiro, Lukáš Vavrečka, Stefan Kock, Jonas Gnauert, Parasitic loads in torque standard machines: a characterization, comparison, and evaluation, Acta IMEKO, vol. 8, no. 3, article 12, September 2019, identifier: IMEKO-ACTA-08 (2019)-03-12

Section Editor: Dušan Agrež, University of Ljubljana, Slovenia

Received May 10, 2018; In final form September 2, 2019; Published September 2019

Copyright: This is an open-access article distributed under the terms of the Creative Commons Attribution 3.0 License, which permits unrestricted use, distribution, and reproduction in any medium, provided the original author and source are credited.

Funding: This work was supported by the European Metrology Programme for Innovation and Research (EMPIR).

Corresponding author: Dirk Röske, e-mail: dirk.roeske@ptb.de

\section{INTRODUCTION}

Metrology institutes and calibration laboratories use torque standard machines (TSMs) with different types of bearings and flexible couplings [1]-[7] for the calibration of torque sensors. These bearings and couplings are designed to reduce parasitic loads to the extent that they can be neglected. Furthermore, the EURAMET cg-14 torque calibration guide [8] recommends averaging the deflections resulting from measurements in three mounting positions. However, to confirm the assumption that parasitic loads can be neglected, a proper metrological description of the TSMs and a validation of this assumption is necessary. The investigation of parasitic loads plays an important role in precision torque calibrations, but it is difficult to prove how mechanical parts such as bearings and flexible couplings reduce parasitic forces and bending moments as well as whether misalignments exist [9]-[11]. An important issue within this field is the need to determine what a realistic order of magnitude for parasitic loads in TSMs is.

Within the scope of the EMPIR project entitled 'Torque Measurement in the MN·m Range' [12], it has become possible for the first time to characterise all parasitic load components. Two different multi-component torque transducers (MCTTs) are used, and numerical, analytical and metrological methods are applied to determine the sensitivity matrices of the transducers. In measurements comparing the three TSMs, these MCTTs are used to determine the acting parasitic loads. The participants in this study are the Physikalisch-Technische Bundesanstalt (PTB, Braunschweig, Germany), Teknologian tutkimuskeskus VTT Oy (VTT, Kajaani, Finland) and Cesky Metrologicky Institut Brno (CMI, Brno, Czech Republic). The order of magnitude and functional dependency of the acting side loads in these TSMs are determined and can be used to further improve the mechanical parts or the adjustment of the TSMs. An easy-to-handle classification system for MCT'Ts is proposed in this article. 


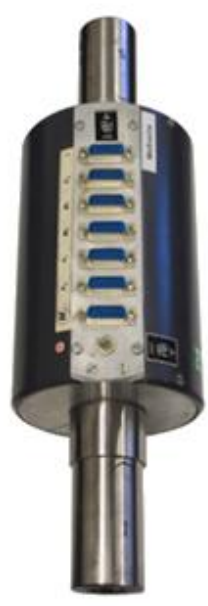

a)



b)

Figure 1. (a) PTB's multi-component torque transducer MCTT and (b) VTT's Raute Precision $2 \mathrm{kN} \cdot \mathrm{m}$ transducer TT1.

\section{MULTI-COMPONENT TORQUE TRANSDUCERS}

We chose a special six-component torque transducer from PTB, shown in Figure 1 (a) [13], and a Raute Precision Oy TT1 from VTT, Figure 1 (b), for the measurements, both with a nominal torque capacity of $2 \mathrm{kN} \cdot \mathrm{m}$. Our aim was to provide a description and comparison of the parasitic loads between the 1 $\mathrm{kN} \cdot \mathrm{m}$ [14] and $20 \mathrm{kN} \cdot \mathrm{m}$ TSMs [15] at PTB; the $2 \mathrm{kN} \cdot \mathrm{m}$ dead weight at VTT; and the $1 \mathrm{kN} \cdot \mathrm{m}$ TSM at CMI. The sensors selected have an equal nominal torque load capacity of $2 \mathrm{kN} \cdot \mathrm{m}$ and identical adaptations (a shaft type with a diameter of $50 \mathrm{~mm}$ and a length of $82 \mathrm{~mm}$ ). Both sensors were calibrated using the procedure defined in EURAMET cg-14. In addition to this standard method for the torque bridge, the electrical signal of all other measurement bridges was simultaneously recorded using an amplifier of type 'DMP41'.

The sensitivity matrices were determined by means of analytical, numerical, and metrological methods. All three methods are presented using PTB's MCTT as an example.
Table 1. Material parameters of PTB's $2 \mathrm{kN} \cdot \mathrm{m}$ MCTT.

$\begin{array}{lll}d & \text { - diameter } & 0.0422 \mathrm{~m} \\ E & \text { - elastic modulus } & 2.11 \cdot 10^{11} \mathrm{~N} \cdot \mathrm{m}^{-2} \\ G & \text { - shear modulus } & 8.12 \cdot 10^{10} \mathrm{~N} \cdot \mathrm{m}^{-2} \\ v & \text { - Poisson's ratio } & 0.3 \\ k & \text { - k-factor } & 2 \\ f & \text { - shape factor } & 1.126\end{array}$

\section{CHARACTERISATION OF PTB'S MCTT}

PTB's MCTT is a non-commercial transducer. Based on the principle of a cylindrical deformation element [16], this sixcomponent transducer can measure the total force and moment vectors. The sensor was developed 25 years ago to measure the torque while compensating all additional contributions ('disturbing components') to the signal of the torque measuring bridge [13]. To perform an analytical and numerical analysis, the dimensions, material parameters, and type of the strain gauges are determined as well as their positions and circuitries (see Figure 2).

\subsection{Analytical description}

The analytical description of the transducer is based on the model of a cylindrical deformation element. Table 1 contains the material parameters. The main strains $\varepsilon$ for each force and moment were calculated by means of Equations (1) to (4). The expected analytical sensitivities $S$ were estimated depending on the circuitry and position of the strain gauges.

$$
\begin{aligned}
& \varepsilon_{F_{x / y}}=\frac{2 \cdot F_{x / y} \cdot f}{\pi \cdot d^{2} \cdot G} \\
& \varepsilon_{F_{z}}=\frac{4 \cdot F_{z}}{\pi \cdot d^{2} \cdot E} \\
& \varepsilon_{M_{x / y}}=\frac{32 \cdot M_{x / y}}{\pi \cdot d^{3} \cdot G} \\
& \varepsilon_{M_{z}}=\frac{8 \cdot M_{z}}{\pi \cdot d^{3} \cdot G}
\end{aligned}
$$
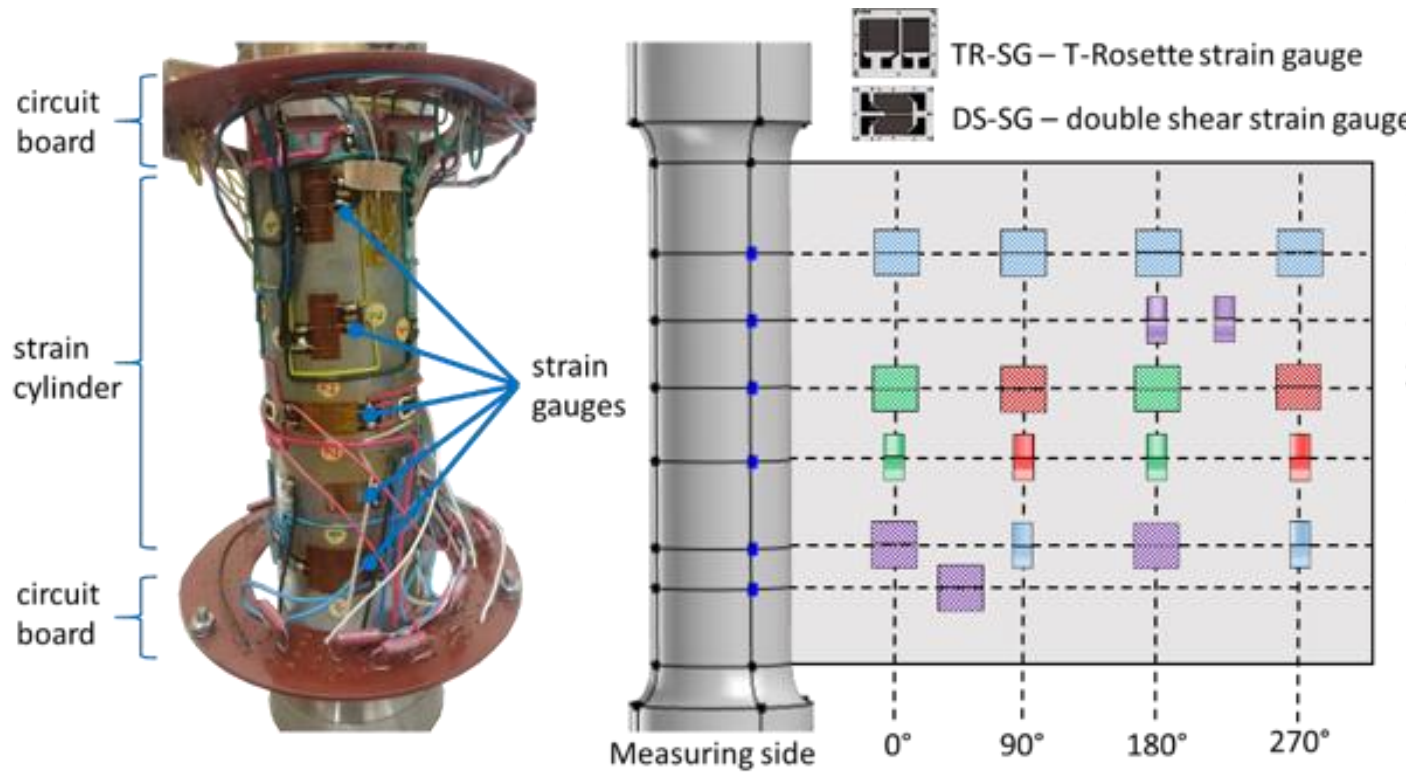

$2 x=D S-S G$ for $F_{x}$ $2 \mathrm{x} \rightleftharpoons \mathrm{DS}-\mathrm{SG}$ for $F_{\mathrm{y}}$ $2 x \cap$ TR-SG for $F_{2}$ 2x 2x TR-SG for $M_{y}$ $4 \mathrm{x} \square \mathrm{DS}-\mathrm{SG}$ for $M_{z}$ DS-SG and TR-SG H for compensation circuitries

Figure 2. Real and schematic picture of the strain gauges and their positions on the PTB $2 \mathrm{kN} \cdot \mathrm{m} \mathrm{MCTT}$. 
Table 2. Estimated analytical sensitivities $s$ and theoretical rated capacities of PTB's $2 \mathrm{kN} \cdot \mathrm{m}$ MCTT.

\begin{tabular}{rlrl}
\hline$S_{F_{x / y}}$ & $=9.92(\mathrm{nV} / \mathrm{V}) / \mathrm{N}$ & $f_{x / y}$ & $=101 \mathrm{kN} /(\mathrm{mV} / \mathrm{V})$ \\
$S_{F_{z}}$ & $=4.40(\mathrm{nV} / \mathrm{V}) / \mathrm{N}$ & $f_{z}$ & $=227 \mathrm{kN} /(\mathrm{mV} / \mathrm{V})$ \\
$S_{M_{x / y}}$ & $=835(\mathrm{nV} / \mathrm{V}) /(\mathrm{N} \cdot \mathrm{m})$ & $m_{x / y}$ & $=1.2 \mathrm{kN} \cdot \mathrm{m} /(\mathrm{mV} / \mathrm{V})$ \\
$S_{M_{z}}$ & $=835(\mathrm{nV} / \mathrm{V}) /(\mathrm{N} \cdot \mathrm{m})$ & $m_{z}$ & $=1.2 \mathrm{kN} \cdot \mathrm{m} /(\mathrm{mV} / \mathrm{V})$ \\
\hline
\end{tabular}

Table 2 summarises the results. Due to the large moment introduced by the cross forces $F_{x / y}$, the nominal force capacity in these directions is much lower (about $10 \mathrm{kN}$ ).

For an ideal shaft-type transducer in which strain gauge bridges have been installed in an ideal way, all bridges except one are mitigated for parasitic components. An axial force, for example, causes strains in the direction of the transducer's axis that are the same for each of the torque bridge strain gauges. Within the Wheatstone bridge, the corresponding resistance changes cancel each other out; thus, the output signal of the torque bridge will not change. An exception to the ideal compensation is the axial force measuring bridge. The strain gauges applied parallel to the torque axis are affected by an additional strain caused by torsion. This effect is explained by the fact that a pure torque acting along the axis of a shaft causes the shaft to twist. This twist is small but measurable. Within the limits of elastic material behaviour, the length of the shaft does not change and remains constant. However, a straight surface line that is parallel to the axis and cannot remain straight will start to turn into a helix, thus becoming longer. In other words, a strain occurs along this line. Moreover, this lengthening takes place regardless of the direction (clockwise or anticlockwise) of the applied torque. This causes the non-linear crosstalk behaviour $S_{F_{z}}\left(M_{Z}\right)$ of the torque on the axial force measuring bridge. The effect is presented theoretically in Figure 3 with a twisting angle of $\theta$.

The strain $\varepsilon_{F_{z}}^{\prime}$ in the force measuring bridge caused by a torque $M_{Z}$ can be calculated using Equation (5) with $d$ being the diameter of the shaft and $G$ the shear modulus of the shaft material. The strain $\varepsilon^{\prime}{ }_{F_{Z}}$ contributes twice to the signal $S_{F_{Z}}\left(M_{Z}\right)$ because of two axially directed strain gauges, which form the opposite legs of the bridge circuit (normally a Wheatstone bridge with four strain gauges) [17]. Compared with the nominal signals of the main bridges which have an order of magnitude of 1 $\mathrm{mV} / \mathrm{V}$, the signal in the axial force measuring bridge caused by the torque load is about three orders of magnitude lower. Some results from measurements in comparison with analytical values are shown in Figure 4.

$$
\varepsilon^{\prime}{ }_{F_{Z}}=\frac{1}{\cos \left(\operatorname{atan}\left(\frac{16 \cdot M_{z}}{\pi \cdot d^{3} \cdot G}\right)\right)}-1
$$

The mean torque sensitivity of the force measuring bridge of $0.0022 \mathrm{mV} / \mathrm{V}$ found in the calibration with clockwise and anticlockwise torques differs from the theoretical value obtained using Equation (5) for an ideal bridge $(0.0014 \mathrm{mV} / \mathrm{V})$. The reason for this deviation has not yet been found. Therefore, a scaling factor $k^{\prime}$ was introduced to account for all influences affecting the mean bridge sensitivity.

The axial force measuring bridge consists of two axially directed strain gauges (upper parts of TR-SG for $F_{z}$ in Figure 2, numbered here as 1 and 3) and two strain gauges parallel to the circumference of the cross-section (the lower parts of the TRSG, numbered 2 and 4). Two strain gauges, one axial and one



$M_{z}=0 \mathrm{~N} \cdot \mathrm{m}$

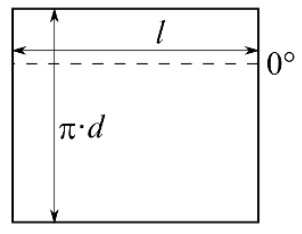

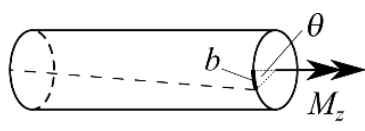

$M_{z} \neq 0 \mathrm{~N} \cdot \mathrm{m}$

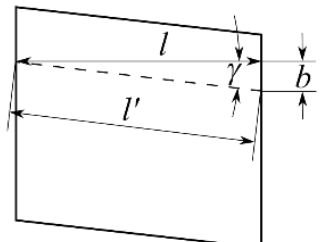

Figure 3. Explanation of the crosstalk from the torque load $M_{\mathrm{z}}$ to the axial force measurement $S_{\mathrm{F}_{\mathrm{z}}}$

circumferential ( 1 and 2 or 3 and 4), are combined on one carrier. Angular displacement of the carrier affects both strain gauges. Angular displacements from the intended position lead to asymmetric signal behaviour for clockwise and anticlockwise torque loads. If the angular positions $\gamma_{i}^{\prime}$ are assumed for the strain gauges $i \in 1,2,3,4$, then the measurable strains $\varepsilon^{\prime \prime}{ }_{F_{z}, i}$ can be calculated by means of Equation (6).

$$
\varepsilon_{F_{z}, i}^{\prime \prime}=\frac{\cos \left(\gamma_{i}^{\prime}\right)}{\cos \left(\operatorname{atan}\left(\tan \left(\gamma_{i}^{\prime}\right)+\frac{16 \cdot M_{z}}{\pi \cdot d^{3} \cdot G}\right)\right)}-1
$$

Here, $\gamma^{\prime}{ }_{1}$ and $\gamma^{\prime}{ }_{3}$ are close to zero, whereas $\gamma^{\prime}{ }_{2}$ and $\gamma_{4}^{\prime}$ are close to $\pi / 2$ with the following relationship: $\gamma_{2 / 4}^{\prime}=\pi / 2+$ $\gamma_{1 / 3}^{\prime}$. The theoretical signal of the Wheatstone bridge can then be taken from Equation (7) [17] with the sensitivity factor $k^{\prime}$.

$$
\begin{aligned}
& S_{F_{z}}\left(\gamma^{\prime}{ }_{i}, M_{z}\right)= \\
& k^{\prime} \cdot \frac{k}{4} \cdot\left(\varepsilon^{\prime \prime}{ }_{F_{Z}, 1}-\varepsilon^{\prime \prime}{ }_{F_{Z}, 2}+\varepsilon^{\prime \prime}{ }_{F_{Z}, 3}-\varepsilon^{\prime \prime}{ }_{F_{Z}, 4}\right)
\end{aligned}
$$

An estimation shows that even a small angular deviation of $0.01^{\circ}(0.00017 \mathrm{rad})$ of one axial strain gauge leads to a relative signal change at $2000 \mathrm{~N} \cdot \mathrm{m}$ of slightly more than $20 \%$. Although the torque-generated signal in the axial force measuring bridge is low, it is much higher than the crosstalk signals in the other bridges. It is also very sensitive to the angular position of the strain gauges. Due to the limited accuracy in the positioning of the strain gauges, asymmetric behaviour as shown for the measured signals in Figure 4 must be expected. The fitted signal function is calculated with the following parameters:

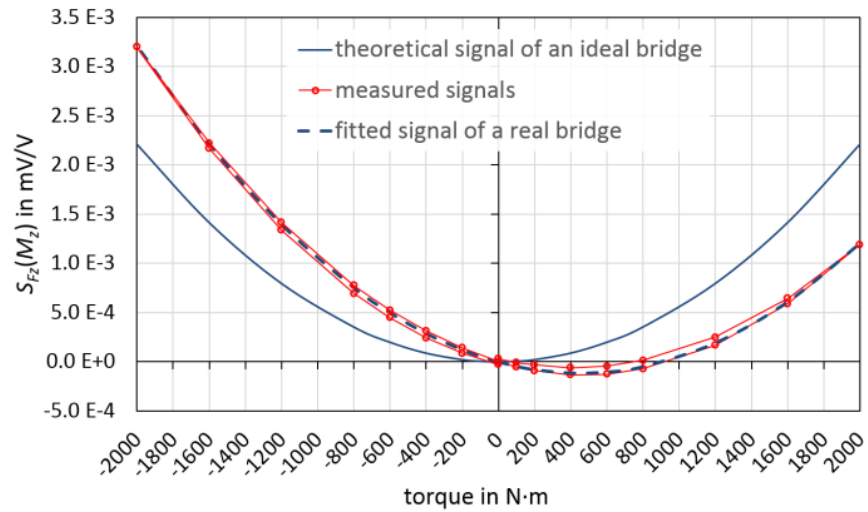

Figure 4. Comparison between the experimental and analytical descriptions of the non-linear crosstalk behaviour of $S_{\mathrm{F}_{\mathrm{z}}}\left(M_{\mathrm{z}}\right)$ 

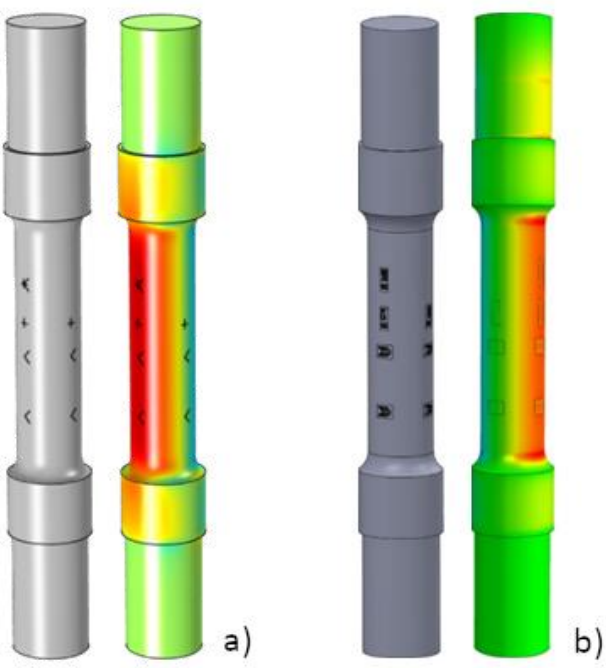

Figure 5. CAD model and result of a load with a bending moment of the PTB MCTT with a) COMSOL and b) Simulia Abaqus.

$\gamma_{1}^{\prime}=-0.00037 \mathrm{rad}\left(0.021^{\circ}\right), \gamma^{\prime}{ }_{3}=-0.00001 \mathrm{rad}, k^{\prime}=$ 1.58. The effect is highly reproducible, allowing corrections to be applied to significantly reduce this crosstalk.

\subsection{Numerical description}

The dimensions of the transducer were detected by means of a coordinate measuring device and transformed into a CAD model. The simulations were carried out using COMSOL Multiphysics and Simulia Abaqus to double-check the results.

In both cases, the strains were simulated at the surface of the transducer according to the real position of the strain gauges as a linear elastic model (see Figure 5). The strain of a single strain gauge is estimated depending on its length and corresponds to the averaged integral value. An averaged integral strain value is a better and more realistic approximation than the single-point analysis of the strain.

According to the circuitry and strain gauge $k$-factors, the strains are converted into a sensitivity in $(\mathrm{mV} / \mathrm{V}) / \mathrm{N}$ and $(\mathrm{mV} / \mathrm{V}) /(\mathrm{N} \cdot \mathrm{m})$ for each component of the force and moment vector. Table 3 and Table 4 contain the results.

\subsection{Metrological description}

A multi-component calibration procedure has been developed based on a lever/mass system (LMS) (see Figure 6). Using the LMS, it is possible to decouple and calibrate singlemeasurement bridges with axial and lateral forces and with bending moments. The measurement range is limited by the

Table 3. Numerical sensitivities $s$ with COMSOL.

$$
\begin{aligned}
S_{F_{x / y}} & =1.07 \cdot 10^{-5}(\mathrm{mV} / \mathrm{V}) / \mathrm{N} \\
S_{F_{Z}} & =4.40 \cdot 10^{-6}(\mathrm{mV} / \mathrm{V}) / \mathrm{N} \\
S_{M_{x / y}} & =8.34 \cdot 10^{-4}(\mathrm{mV} / \mathrm{V}) /(\mathrm{N} \cdot \mathrm{m}) \\
S_{M_{Z}} & =8.29 \cdot 10^{-4}(\mathrm{mV} / \mathrm{V}) /(\mathrm{N} \cdot \mathrm{m})
\end{aligned}
$$

Table 4. Numerical sensitivities $s$ with Simulia Abaqus.

$$
\begin{aligned}
s_{F_{x / y}} & =1.07 \cdot 10^{-5}(\mathrm{mV} / \mathrm{V}) / \mathrm{N} \\
S_{F_{z}} & =4.40 \cdot 10^{-6}(\mathrm{mV} / \mathrm{V}) / \mathrm{N} \\
S_{M_{x / y}} & =8.34 \cdot 10^{-4}(\mathrm{mV} / \mathrm{V}) /(\mathrm{N} \cdot \mathrm{m}) \\
S_{M_{Z}} & =8.29 \cdot 10^{-4}(\mathrm{mV} / \mathrm{V}) /(\mathrm{N} \cdot \mathrm{m})
\end{aligned}
$$

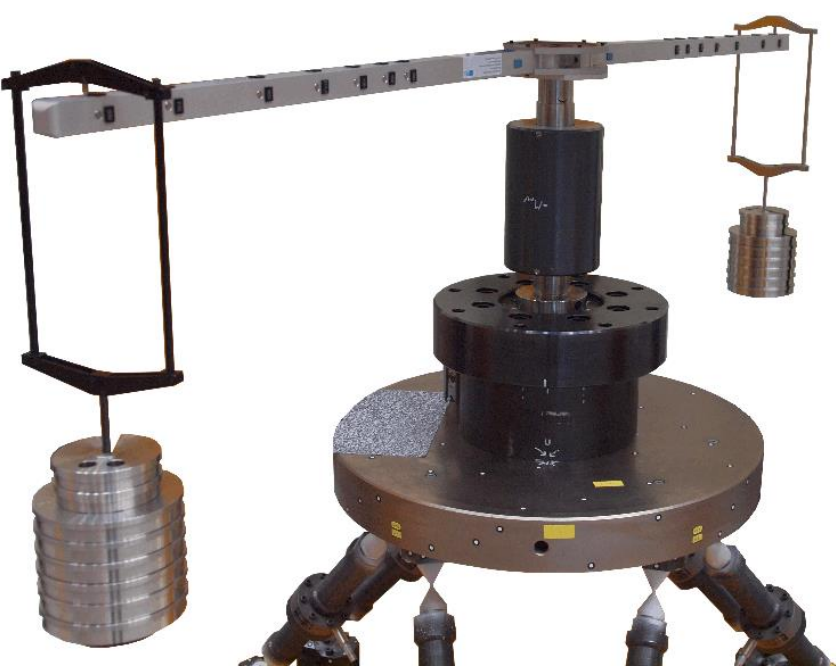

Figure 6. Lever/mass system and MCTT mounted in the measurement hexapod at PTB.

mounting space to $F_{i}=300 \mathrm{~N}$ and $M_{i}=120 \mathrm{~N} \cdot \mathrm{m}$. The lever arm deforms depending on the load applied. This effect and the manufacturing tolerance of each length were measured by means of a coordinate measuring device, and correction factors for the lever arm length were derived.

It should be noted that these loads are in the lower measuring range of the transducers. The aim of the multi-component calibration is to generate a feasibility study; here, calibrating all measurement bridges, and later, reducing the uncertainty, which requires the most effort.

The upper estimation of the single-component calibration is in the range of less than $1 \%$. For a multi-component transducer, this regression analysis must be extended to include higher dimensions (a so-called multi-polynomial regression analysis).

The unknown sensitivity matrix can be estimated by using the pseudo-inverse matrix, as shown in Equation (8). The matrix $\boldsymbol{S}$ represents the output signals; $\boldsymbol{L}$ is the load matrix and contains the combination of the acting loads; and $\boldsymbol{\theta}$ includes the unknown parameter.

$$
\widehat{\boldsymbol{\theta}}=\left(\boldsymbol{L}^{T} \boldsymbol{L}\right)^{-1} \boldsymbol{L}^{T} \boldsymbol{S}
$$

\subsection{Comparison description, PTB}

All three methods are equivalent and lead to sensitivities for the transducer that are identical in an ideal case. In a comparison between these methods, the relative deviations should be zero. It is obvious that the deviation is greater than zero because of inaccurate information and precise values about material parameters, strain gauges, and electrical circuits.

Due to the fact that the measurement results have an inaccuracy of $13.3 \%$ because of the sinusoidal dependency over three mounting positions (section 4.1), the relative deviation should be in a range smaller than $10 \%$; otherwise, the approach of one of the methods will be incorrect. Table 5 shows that the relative deviations between the measurements and the numerical results are in the range of $6 \%$ and below. This can be accounted for by the fact that the simulations include only a rough approximation of a strain gauge. The analytical results are in the range of $7.8 \%$ and below. The results of all three methods are in good agreement for a quantitative description of the sensitivity matrix, which is the aim of this study. However, several options 
Table 5. Comparison between the experimental, analytical, and numerical results of PTB's MCTT.

\begin{tabular}{cccc}
\hline & $\begin{array}{c}\text { measurement/ } \\
\text { analytical }\end{array}$ & $\begin{array}{c}\text { measurement/ } \\
\text { numeric }\end{array}$ & $\begin{array}{c}\text { analytic/ } \\
\text { numeric }\end{array}$ \\
\hline$S_{F_{x}}$ & $3.65 \%$ & $-5.39 \%$ & $8.57 \%$ \\
$S_{F_{y}}$ & $7.77 \%$ & $-0.88 \%$ & $8.57 \%$ \\
$S_{F_{Z}}$ & $-2.05 \%$ & $-2.05 \%$ & $0.00 \%$ \\
$S_{M_{X}}$ & $1.10 \%$ & $0.74 \%$ & $0.36 \%$ \\
$S_{M_{y}}$ & $-0.33 \%$ & $-0.70 \%$ & $0.36 \%$ \\
$S_{M_{Z}}$ & $-5.76 \%$ & $-5.76 \%$ & $0.00 \%$ \\
\hline
\end{tabular}

exist for improving these methods and reducing relative deviations, such as the simulation of real strain gauges.

\subsection{Comparison description, VTT}

All three methods were also applied to the Raute Precision Oy TT1 $2 \mathrm{kN} \cdot \mathrm{m}$ transducer of VTT. The TT1 is only capable of measuring moment vectors but has two additional measurement bridges for bending moments.

Table 6 shows the comparison of the relative deviations. The relative deviation between the measurements and the numerical results is within the range of less than $1 \%$ whereas almost all deviations for the experiment are less than $5 \%$.

\section{COMPARISON MEASUREMENTS}

Within the scope of the EMPIR project [12], both transducers were calibrated with a torque load, and the signal crosstalk behaviour was recorded. In addition, a comparison measurement was carried out. The signal crosstalk of the PTB MCTT was measured in the $20 \mathrm{kN} \cdot \mathrm{m}$ TSM (Figure 7 (a)) and $1 \mathrm{kN} \cdot \mathrm{m}$ TSM (Figure 7 (b)) at PTB, in the $2 \mathrm{kN} \cdot \mathrm{m}$ TSM at VTT (Figure 7 (c)), and in the $1 \mathrm{kN} \cdot \mathrm{m}$ TSM at CMI (Figure 7 (d)).

The Raute Precision Oy TT1 $2 \mathrm{kN} \cdot \mathrm{m}$ transducer at VTT was used to double-check the results; however, only the bending moments were compared. In the first approximation, acting parasitic loads were considered independent of the mounted transducer. For the calculation of the parasitic loads and for the main components, the sensitivity matrix of the experiment method was used (Table 7).

\subsection{Crosstalk signals for a $20 \mathrm{kN} \cdot \mathrm{m}$ torque calibration}

The behaviour of the signal $S$ does not correlate directly with an acting parasitic load. It consists of acting forces and moments from the TSM on the one hand and one of the following crosstalk sensitivities from the MCTT on the other hand (depending on the torque applied): $S_{F_{x}}\left(M_{z}\right), S_{F_{y}}\left(M_{z}\right), S_{F_{z}}\left(M_{z}\right)$, $S_{M_{x}}\left(M_{z}\right)$, and $S_{M_{y}}\left(M_{z}\right)$. Figure 8 shows this coherence of the

Table 6. Comparison between the experimental, analytical, and numerical sensitivity results of the VTT MCTT.

\begin{tabular}{cccc}
\hline & $\begin{array}{c}\text { measurement/ } \\
\text { analytical }\end{array}$ & $\begin{array}{c}\text { measurement/ } \\
\text { numeric }\end{array}$ & $\begin{array}{c}\text { analytic/ } \\
\text { numeric }\end{array}$ \\
\hline$S_{F_{X}}$ & $4.16 \%$ & $4.87 \%$ & $-0.75 \%$ \\
$S_{F_{y}}$ & $4.23 \%$ & $4.94 \%$ & $-0.74 \%$ \\
$S_{F_{z}}$ & $4.11 \%$ & $4.82 \%$ & $-0.75 \%$ \\
$S_{M_{X}}$ & $4.32 \%$ & $5.03 \%$ & $-0.74 \%$ \\
$S_{M_{y}}$ & $-3.53 \%$ & $-2.64 \%$ & $-0.87 \%$ \\
$S_{M_{Z}}$ & $4.16 \%$ & $4.87 \%$ & $-0.75 \%$ \\
\hline
\end{tabular}


Figure 7. Torque standard machines used in the study: a) $20 \mathrm{kN} \cdot \mathrm{m}$ TSM [15] and b) $1 \mathrm{kN} \cdot \mathrm{m}$ TSM [14] at PTB; c) $2 \mathrm{kN} \cdot \mathrm{m}$ TSM at VTT; d) $1 \mathrm{kN} \cdot \mathrm{m}$ TSM at CMI. 
Table 7. Experimentally determined sensitivity matrix of PTB's $2 \mathrm{kN} \cdot \mathrm{m} \mathrm{MCTT}$ in $(\mathrm{mV} / \mathrm{V}) / \mathrm{N}$ and $(\mathrm{mV} / \mathrm{V}) /(\mathrm{N} \cdot \mathrm{m})$.

\begin{tabular}{ccccccc}
\hline & $S\left(F_{x}\right)$ & $S\left(F_{y}\right)$ & $S\left(F_{z}\right)$ & $S\left(M_{x}\right)$ & $S\left(M_{y}\right)$ & $S\left(M_{z}\right)$ \\
\hline$F_{x}$ & $1.03 \cdot 10^{-5}$ & $-5.75 \cdot 10^{-8}$ & $3.64 \cdot 10^{-7}$ & $2.48 \cdot 10^{-6}$ & $-1.56 \cdot 10^{-5}$ & $4.26 \cdot 10^{-8}$ \\
$F_{y}$ & $-1.15 \cdot 10^{-7}$ & $1.08 \cdot 10^{-5}$ & $7.81 \cdot 10^{-8}$ & $-1.52 \cdot 10^{-5}$ & $-4.47 \cdot 10^{-6}$ & $-3.19 \cdot 10^{-8}$ \\
$F_{z}$ & $-7.06 \cdot 10^{-8}$ & $1.04 \cdot 10^{-7}$ & $-4.31 \cdot 10^{-6}$ & $6.87 \cdot 10^{-8}$ & $-1.46 \cdot 10^{-7}$ & $-6.97 \cdot 10^{-8}$ \\
$M_{x}$ & $8.35 \cdot 10^{-7}$ & $-2.73 \cdot 10^{-7}$ & $-3.93 \cdot 10^{-6}$ & $8.44 \cdot 10^{-4}$ & $-7.53 \cdot 10^{-6}$ & $-5.68 \cdot 10^{-7}$ \\
$M_{y}$ & $5.85 \cdot 10^{-8}$ & $8.05 \cdot 10^{-7}$ & $1.45 \cdot 10^{-8}$ & $-6.42 \cdot 10^{-6}$ & $8.32 \cdot 10^{-4}$ & $2.82 \cdot 10^{-7}$ \\
$M_{z}$ & $1.13 \cdot 10^{-8}$ & $-5.05 \cdot 10^{-8}$ & $3.59 \cdot 10^{-7}$ & $-2.78 \cdot 10^{-7}$ & $4.98 \cdot 10^{-6}$ & $7.90 \cdot 10^{-4}$ \\
\hline
\end{tabular}

signal crosstalk of the PTB MCTT during the torque calibration in the $20 \mathrm{kN} \cdot \mathrm{m}$ TSM.

The two influencing factors must be decoupled. For example, in Figure 8, the signal for the bending moments $S_{M_{x}}\left(M_{z}\right)$ and $S_{M_{y}}\left(M_{z}\right)$ differs by one order of magnitude, although they should be the same. To solve this problem, and in accordance with EURAMET cg-14, we assume that the averaged crosstalk signal $\bar{S}_{i}$ over three mounting positions $\left(0^{\circ}-120^{\circ}-240^{\circ}\right)$

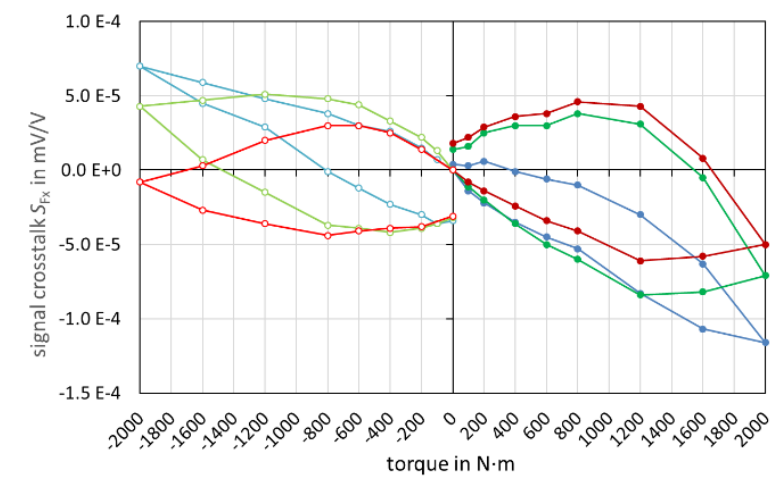

a)

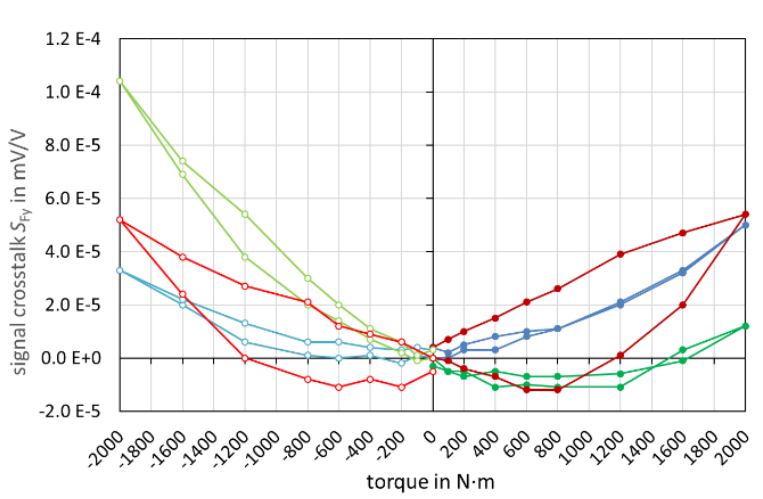

b)
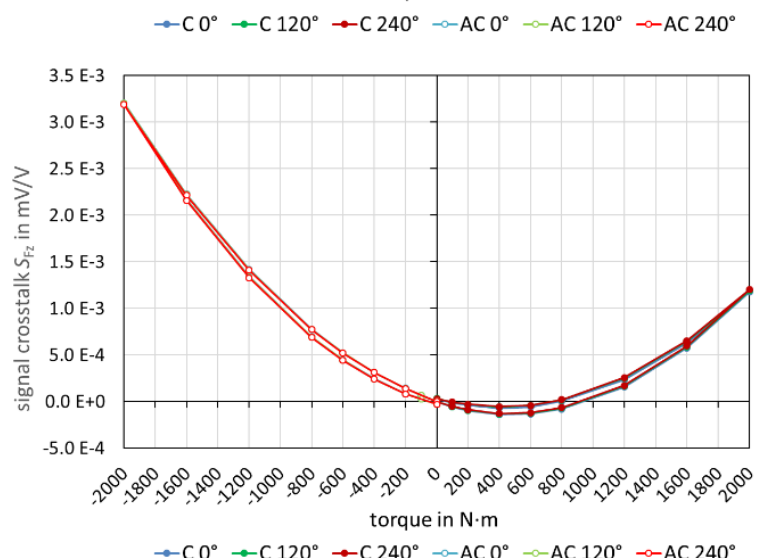

c)

$$
\rightarrow-\mathrm{C} 0^{\circ} \rightarrow-\mathrm{C} 120^{\circ} \rightarrow \mathrm{C} 240^{\circ} \rightarrow-\mathrm{AC} 0^{\circ} \rightarrow-\mathrm{AC} 120^{\circ} \rightarrow-\mathrm{AC} 240^{\circ}
$$

corresponds to the crosstalk sensitivity. This logical assumption can be made because acting bending moments, and lateral forces should have a rotatory effect on the signal of the transducer. For this reason, the difference $\Delta S_{i}$ in Equation (9) between the measured signal $S_{i}$ and the averaged signal $\bar{S}_{i}$

$$
\Delta S_{i}=\bar{S}_{i}-S_{i}
$$

shows the influence of the acting parasitic loads.

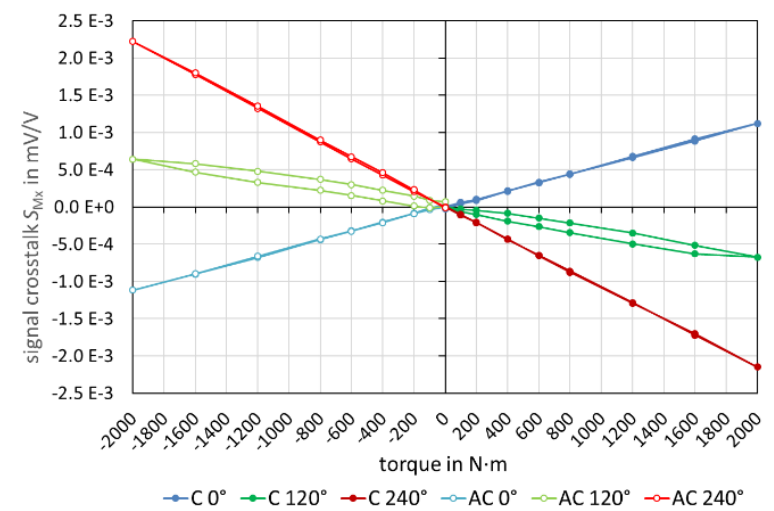

d)

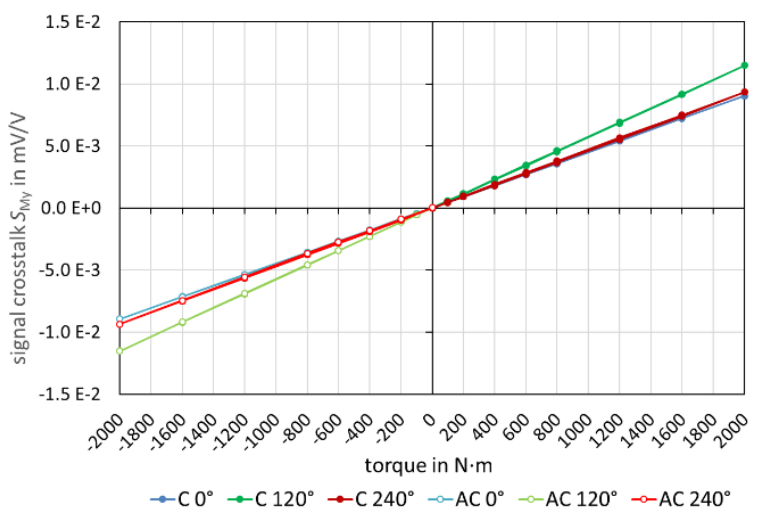

e)

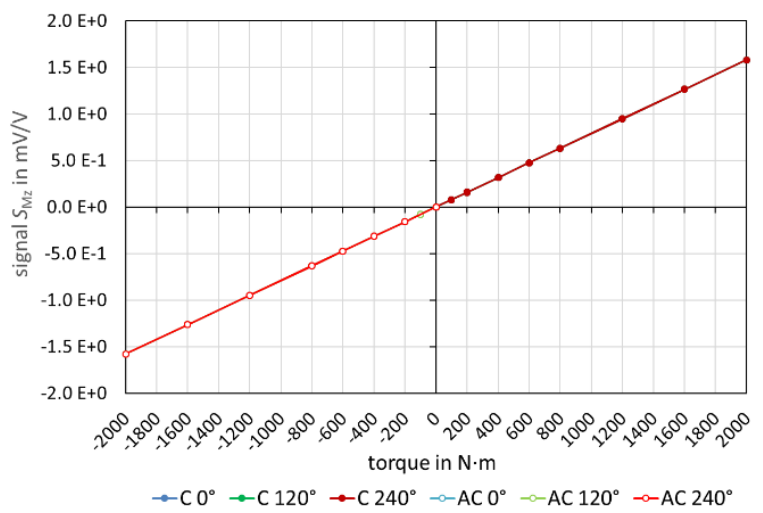

f)

Figure 8. Crosstalk signal behaviour of the PTB MCTT during the torque calibration in the $20 \mathrm{kN} \cdot \mathrm{m}$ TSM: a) $S_{\mathrm{Fx}}$, b) $\left.S_{\mathrm{Fy}}, \mathrm{c}\right) S_{\mathrm{Fz}}$, d) $S_{\mathrm{Mx}}$, e) $S_{\mathrm{My}}$ and f) signal $S_{\mathrm{Fz}}$. Here and in the following: $\mathrm{C}$ - clockwise torque, $\mathrm{AC}$ - anti-clockwise torque, $0^{\circ}, 120^{\circ}, 240^{\circ}$-mounting position of the transducer. 




a)
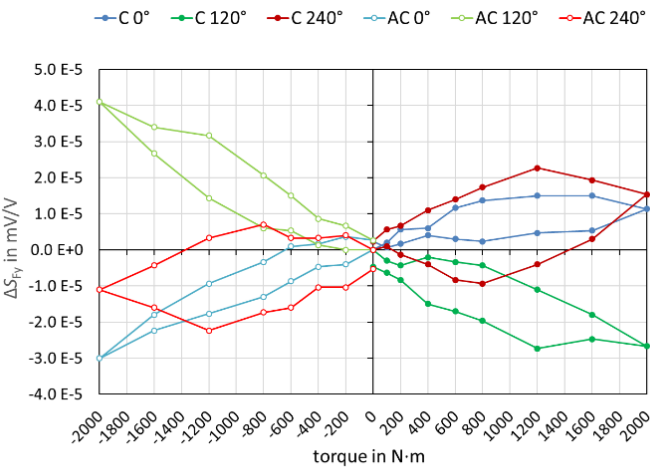

b) $\rightarrow \mathrm{C} 0^{\circ} \rightarrow \mathrm{C} 120^{\circ} \rightarrow \mathrm{C} 240^{\circ} \rightarrow \mathrm{AC} 0^{\circ} \rightarrow \mathrm{AC} 120^{\circ} \rightarrow \mathrm{AC} 240^{\circ}$

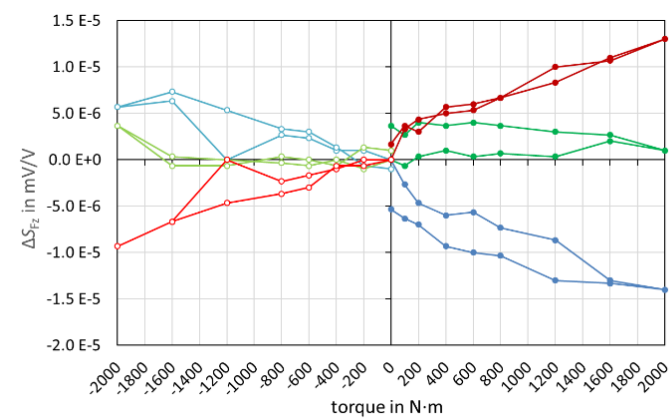

c)



d)

$\rightarrow \mathrm{C} 0^{\circ} \rightarrow \mathrm{C} 120^{\circ} \rightarrow \mathrm{C} 240^{\circ} \rightarrow \mathrm{AC} 0^{\circ}-\mathrm{AC} 120^{\circ} \rightarrow \mathrm{AC} 240^{\circ}$

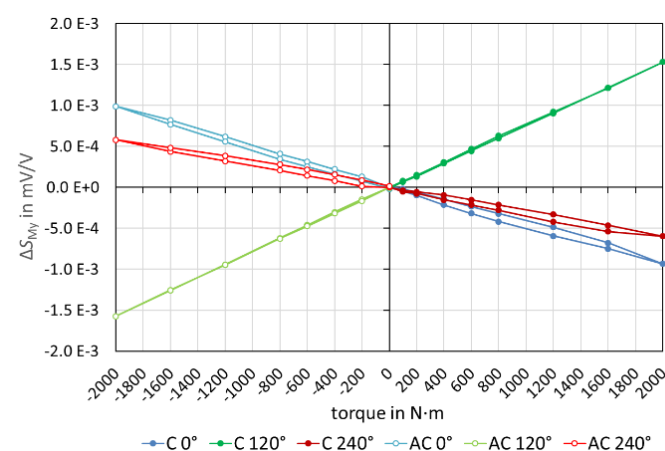

e)

Figure 9. Difference between the crosstalk signal and the average crosstalk signal of the measuring series: a) $S_{\mathrm{Fx}}$, b) $S_{\mathrm{Fy}}$, c) $S_{\mathrm{Fz}}$ d) $S_{\mathrm{Mx}}$ and e) $S_{\mathrm{My}}$.
Figure 9 shows the different signals $\Delta S_{i}$. The influence of the lateral forces and the bending moments then has the same order of magnitude and shows the expected rotatory dependency over the three mounting positions. By means of a sensitivity matrix, the electrical signals can be converted into force and moment values.

Because the sinusoidal function is not fitted, the maximum amplitude must be estimated. For three data points at an angular distance of $120^{\circ}$ to each other, the maximum deviation from the maximum amplitude is $1-\sqrt{3} / 2$ (see Figure 10 ); in other words, an upper estimation for lateral forces and bending moments is $13.4 \%$.

\subsection{Parasitic loads of the $20 \mathrm{kN} \cdot \mathrm{m}$ TSM at PTB}

Figure 11 shows the results for the parasitic loads of the $20 \mathrm{kN} \cdot \mathrm{m}$ TSM in the range up to $2 \mathrm{kN} \cdot \mathrm{m}$ for clockwise and anticlockwise torque loads. The transducer was measured in three different mounting positions $\left(0^{\circ}, 120^{\circ}\right.$, and $\left.240^{\circ}\right)$ in accordance with EURAMET cg-14 [8].

The results for the lateral forces $F_{x}$ and $F_{y}$ are in the range of less than $\pm 4 \mathrm{~N}$. In consideration of the upper estimation for the relative uncertainty of a sinusoidal dependency, the results $F_{x}$ and $F_{y}$ will be in the range of at least $\pm 4.54 \mathrm{~N}$. The axial force $F_{z}$ is in the range of $\pm 3 \mathrm{~N}$, and the acting bending moments $M_{x}$ and $M_{y}$ are in the range of less than $\pm 2.37 \mathrm{~N} \cdot \mathrm{m}$.

Figure 12 shows the comparison results with the Raute Precision Oy TT1 $2 \mathrm{kN} \cdot \mathrm{m}$ transducer at VTT in the $20 \mathrm{kN} \cdot \mathrm{m}$ TSM of the PTB for the parasitic loads. The results for the acting bending moments $M_{x}$ and $M_{y}$ are in the range of less than $\pm 1.7 \mathrm{~N} \cdot \mathrm{m}$.

The reason for the different functional dependencies between Figure 11 and Figure 12 lies in the different sensitivities of both MCT'Ts. The MCT'T of the VTT is much less sensitive for bending moments. The results of both transducers are in the same order of magnitude, which is a good agreement.

\subsection{Parasitic loads of the $1 \mathrm{kN} \cdot \mathrm{m}$ TSM at PTB}

Figure 13 shows the results for the parasitic loads of the $1 \mathrm{kN} \cdot \mathrm{m}$ TSM in the range up to $1 \mathrm{kN} \cdot \mathrm{m}$ for clockwise and anticlockwise torque loads. The results for the lateral forces $F_{x}$ and $F_{y}$ are in the range of less than $\pm 3.4 \mathrm{~N}$. The axial force $F_{z}$ is in the range of $\pm 2.5 \mathrm{~N}$ and the acting bending moments $M_{x}$ and $M_{y}$ are in the range of less than $\pm 1.7 \mathrm{~N} \cdot \mathrm{m}$.

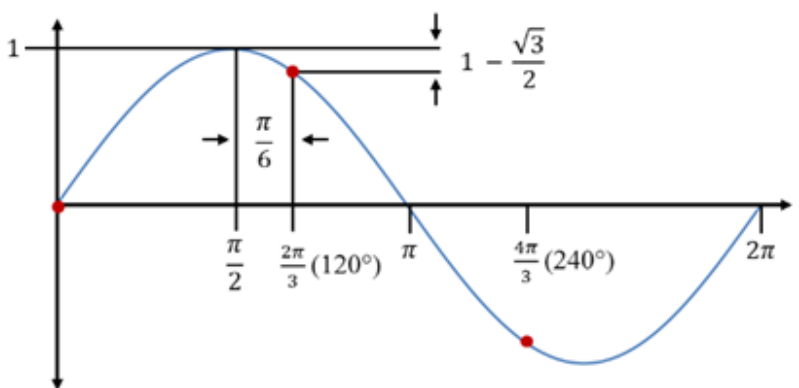

Figure 10. Maximum deviation for a sinusoidal function based on three points with a $120^{\circ}$ distance. 


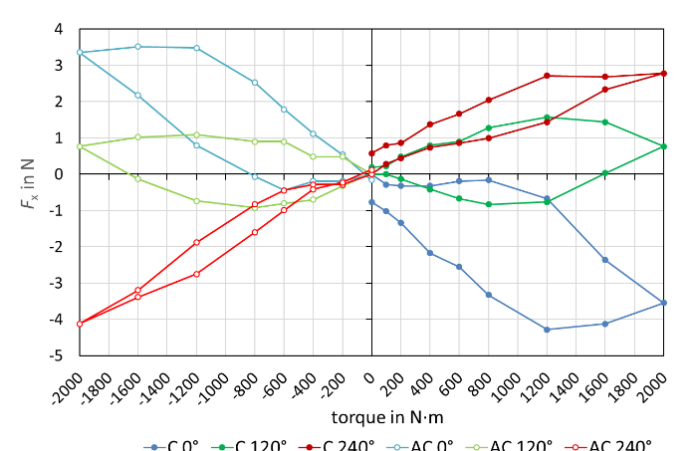

a)

$\rightarrow-\mathrm{C} 0^{\circ} \rightarrow-\mathrm{C} 120^{\circ} \rightarrow \mathrm{C} 240^{\circ} \rightarrow \mathrm{AC} 0^{\circ} \rightarrow \mathrm{AC} 120^{\circ} \rightarrow \mathrm{AC} 240^{\circ}$

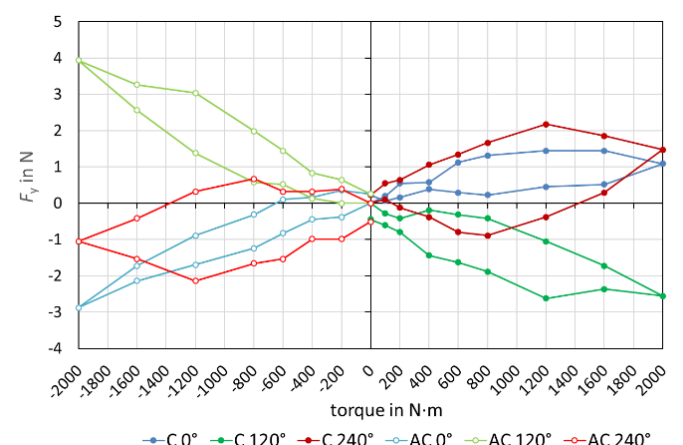

b)



c)

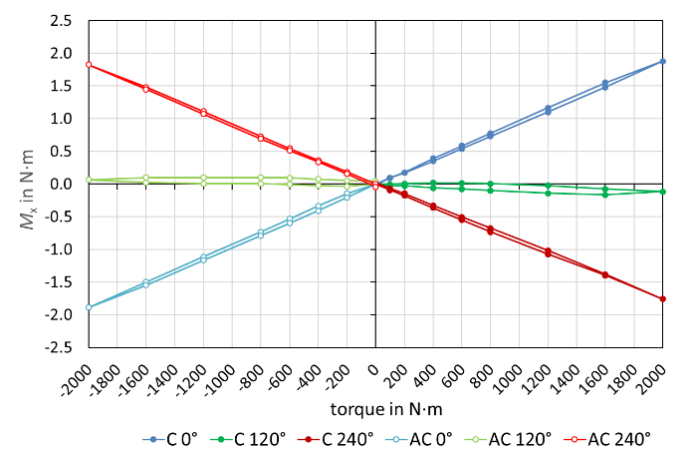

d)

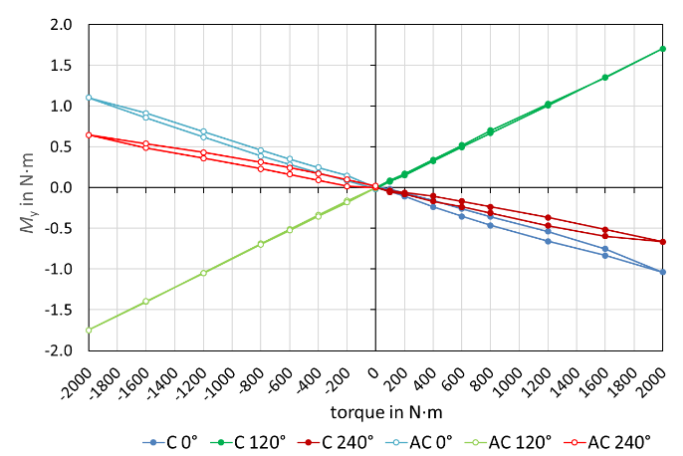

e)

Figure 11. Parasitic loads of the $20 \mathrm{kN} \cdot \mathrm{m}$ TSM at PTB estimated with the PTB MCTT: a) $F_{\mathrm{x}}$ b) $F_{\mathrm{y}}$, c) $F_{z}$, d) $M_{\mathrm{x}}$ and e) $M_{\mathrm{y}}$.

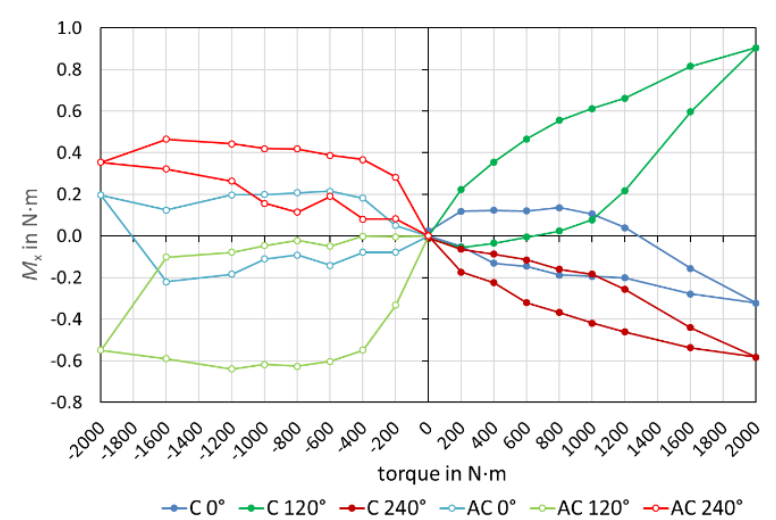

a)

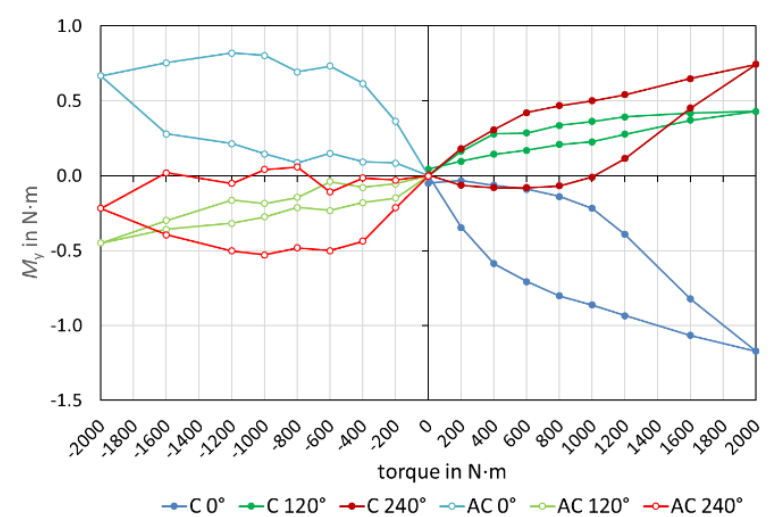

Figure 12. Parasitic loads of the $20 \mathrm{kN} \cdot \mathrm{m}$ TSM at PTB estimated with the VTT MCTT (only bending moments possible): a) $M_{\mathrm{x}}$ and b) $M_{\mathrm{y}}$.

\subsection{Parasitic loads of the $\mathbf{2} \mathrm{kN} \cdot \mathrm{m}$ TSM at VTT}

Figure 14 shows the results for the parasitic loads of the $2 \mathrm{kN} \cdot \mathrm{m}$ TSM in the range of up to $2 \mathrm{kN} \cdot \mathrm{m}$ for clockwise and anticlockwise torque loads. The results for the lateral forces $F_{x}$ and $F_{y}$ are in the range of less than $\pm 17 \mathrm{~N}$. The axial force $F_{z}$ is in the range of $\pm 4.0 \mathrm{~N}$, and the acting bending moments $M_{x}$ and $M_{y}$ are in the range of less than $\pm 1.7 \mathrm{~N} \cdot \mathrm{m}$.

Figure 15 shows the comparison results of the Raute Precision Oy TT1 $2 \mathrm{kN} \cdot \mathrm{m}$ transducer at VTT for the parasitic loads. The results for the acting bending moments $M_{x}$ and $M_{y}$ are in the range of less than $\pm 4.0 \mathrm{~N} \cdot \mathrm{m}$. Two counter-rotating deep-groove ball bearings are used in this TSM. This may be the reason for the nonlinear dependency, the hysteresis and the less reproducible magnitude of the bending moments, as well as for the large lateral forces. Contrary to the expectation that the side loads should be a linear function of the applied torque, non-linear behaviour can be observed in the $2 \mathrm{kN} \cdot \mathrm{m}$ TSM at VTT. This could be an indication that the type of bearings has a significant influence on the torque calibration. If, upon reversion, the bearings demonstrate non-linear transmission behaviour, this might also influence the torque calibration (especially the linearity and the hysteresis characteristics).

\subsection{Parasitic loads of the $1 \mathrm{kN} \cdot \mathrm{m}$ TSM at CMI}

Figure 16 shows the results for the parasitic loads of the $1 \mathrm{kN} \cdot \mathrm{m}$ TSM in the range up to $1 \mathrm{kN} \cdot \mathrm{m}$ for clockwise and anticlockwise torque loads.

The results for the lateral forces $F_{x}$ and $F_{y}$ are in the range of less than $\pm 3.4 \mathrm{~N}$. The axial force $F_{z}$ is in the range of $\pm 5.0 \mathrm{~N}$ and the acting bending moments $M_{x}$ and $M_{y}$ are in the range of less than $\pm 1.1 \mathrm{~N} \cdot \mathrm{m}$. 


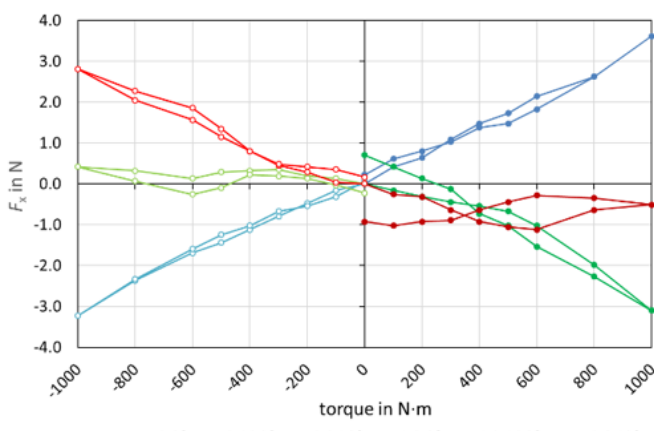

a)

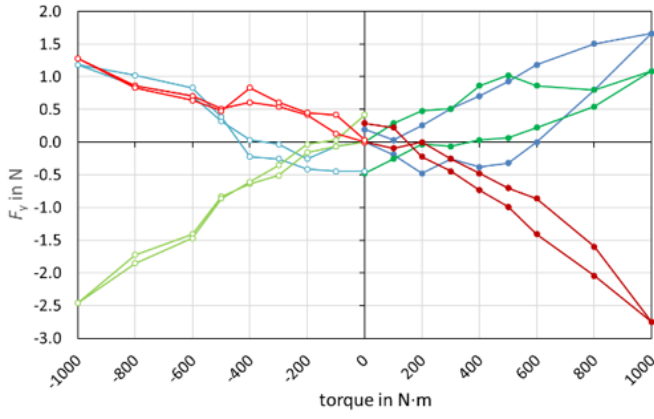

b)

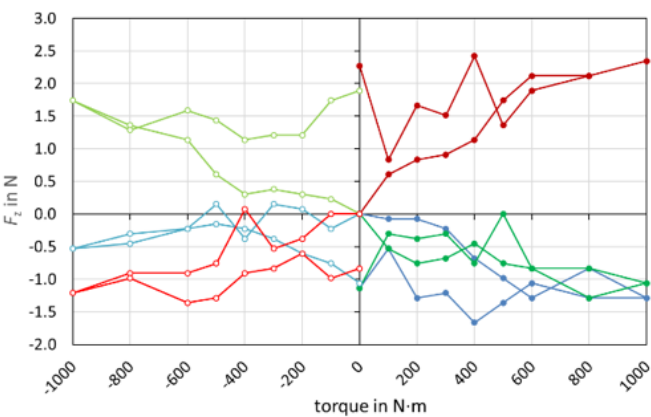

c)

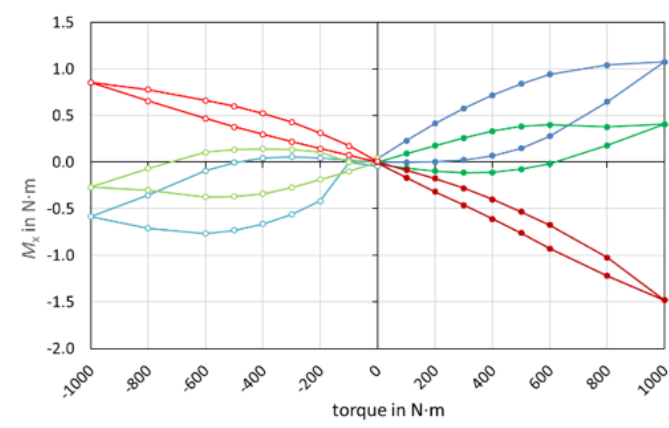

d)

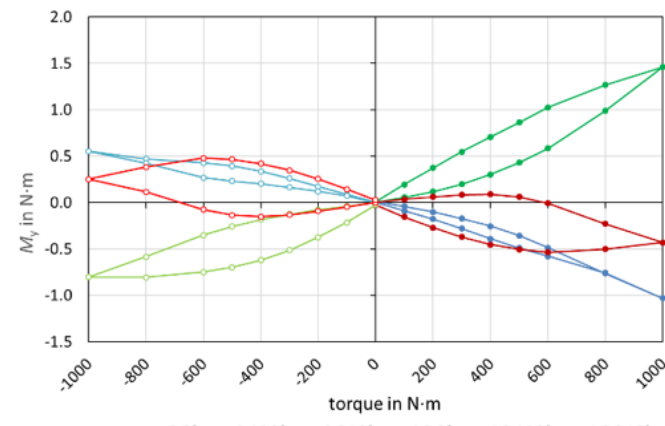

e)

$\rightarrow \mathrm{C} 0^{\circ} \rightarrow \mathrm{C} 120^{\circ} \rightarrow \mathrm{C} 240^{\circ} \rightarrow \mathrm{AC} 0^{\circ} \rightarrow \mathrm{AC} 120^{\circ} \rightarrow \mathrm{AC} 240^{\circ}$

Figure 13. Parasitic loads of the $1 \mathrm{kN} \cdot \mathrm{m}$ TSM at PTB estimated with the PTB MCTT: a) $F_{x}$, b) $F_{y}$, c) $F_{z}$ d) $M_{x}$ and e) $M_{y}$.

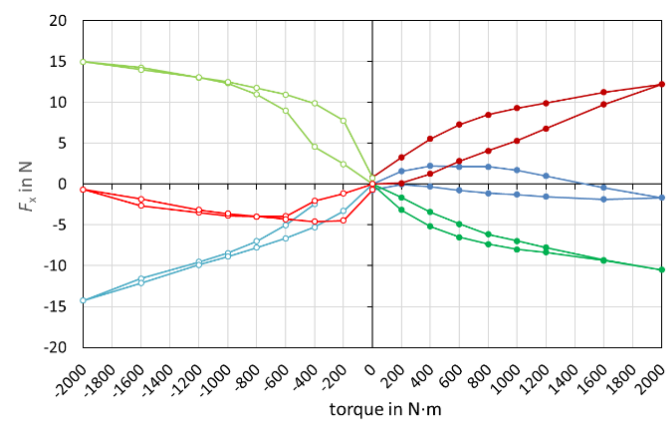

a) $\rightarrow-\mathrm{C} 0^{\circ} \rightarrow-\mathrm{C} 120^{\circ} \rightarrow-\mathrm{C} 240^{\circ} \rightarrow-\mathrm{AC} 0^{\circ} \rightarrow-\mathrm{AC} 120^{\circ} \rightarrow-\mathrm{AC} 240^{\circ}$

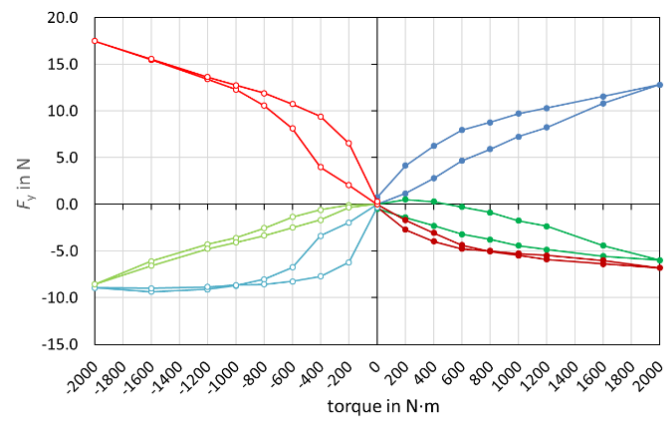

b)





c) $\rightarrow \mathrm{C} 0^{\circ} \rightarrow \mathrm{C} 120^{\circ} \rightarrow \mathrm{C} 240^{\circ} \rightarrow \mathrm{AC} 0^{\circ} \rightarrow \mathrm{AC} 120^{\circ} \rightarrow \mathrm{AC} 240^{\circ}$

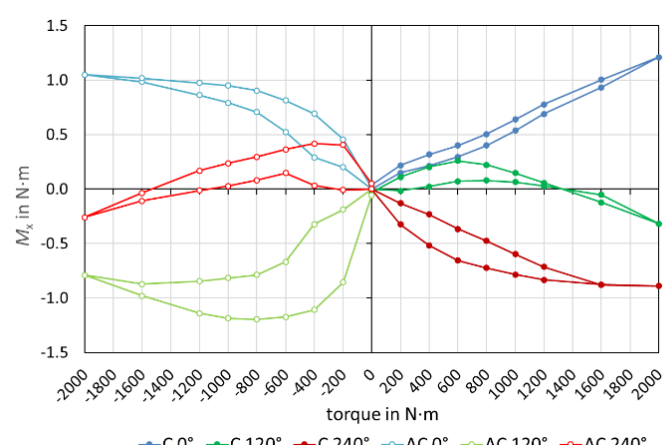

d) $\rightarrow-\mathrm{C} 0^{\circ} \rightarrow-\mathrm{C} 120^{\circ} \rightarrow-\mathrm{C} 240^{\circ} \rightarrow-\mathrm{AC} 0^{\circ} \rightarrow-\mathrm{AC} 120^{\circ} \rightarrow-\mathrm{AC} 240^{\circ}$

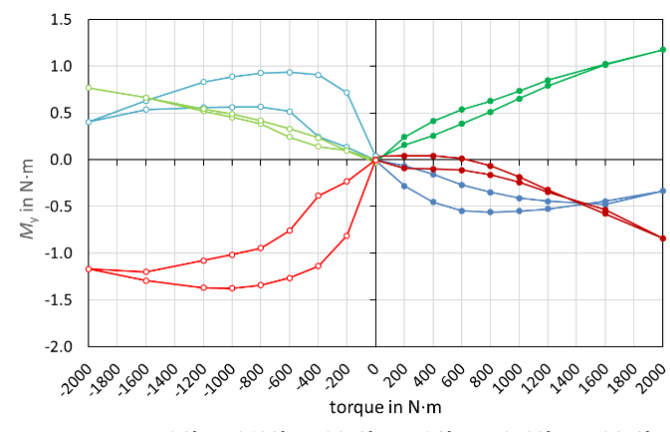

e)

$\rightarrow \mathrm{C} 0^{\circ} \rightarrow \mathrm{C} 120^{\circ} \rightarrow \mathrm{C} 240^{\circ} \rightarrow \mathrm{AC} 0^{\circ} \rightarrow \mathrm{AC} 120^{\circ} \rightarrow \mathrm{AC} 240^{\circ}$

Figure 14. Parasitic loads of the $2 \mathrm{kN} \cdot \mathrm{m}$ TSM at VTT estimated with the PTB MCTT: a) $F_{x}$ b) $F_{y}$, c) $F_{z}$ d) $M_{x}$ and e) $M_{y}$. 




a)

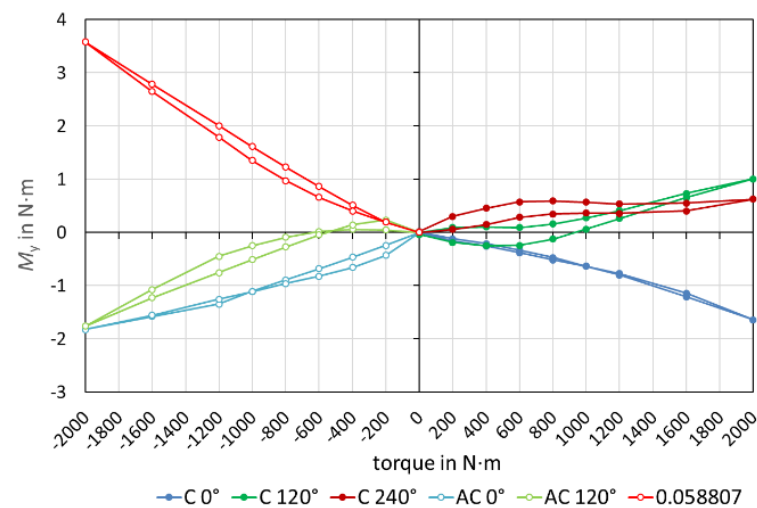

Figure 15. Parasitic loads of the $2 \mathrm{kN} \cdot \mathrm{m}$ TSM at VTT estimated with the VTT MCTT (only bending moments possible): a) $M_{x}$ and b) $M_{y}$.

\section{DISCUSSION}

\subsection{Comparison between PTB's and VTT's MCTT}

A direct comparison is possible only for the bending moments. The results demonstrate good agreement: the difference for the $20 \mathrm{kN} \cdot \mathrm{m}$ TSM at PTB is in the range of $0.5 \mathrm{~N} \cdot \mathrm{m}$; for the $2 \mathrm{kN} \cdot \mathrm{m}$ TSM at VTT, the difference is in the range of $2 \mathrm{~N} \cdot \mathrm{m}$.

The two counter-rotating deep-groove ball bearings used in the $2 \mathrm{kN} \cdot \mathrm{m}$ TSM at VTT may explain the remaining deviations. These bearings might cause additional, non-repeatable bending moments and large lateral-force components.

However, due to the lack of other MCT'Ts, it was not possible to double-check the results for the force vector $\vec{F}$. Based on the comparison of the experimental, analytical, and numerical results of Table 5 , the relative deviations of the component values of the force vector should be less than $8 \%$.

\subsection{Comparison between PTB, VTT and CMI TSMs}

The results of Figure 11 to Figure 16 show the order of magnitude of parasitic loads in the TSMs of the participating NMIs. These results represent the first-ever such comparison.

Table 8 shows the relative magnitude of each maximum side loads with respect to the nominal torque load of each TSM. All results are in the range of less than $0.5 \%$, except for the lateral forces of the $2 \mathrm{kN} \cdot \mathrm{m}$ TSM at VTT, which have a value of $0.85 \%$.

No evaluation criteria exist for deciding whether an additional component could be neglected or not. Whether or not such a component can be considered negligible also depends on other factors such as the transducer sensitivity and the calibration procedure used. However, the relative magnitude may be an

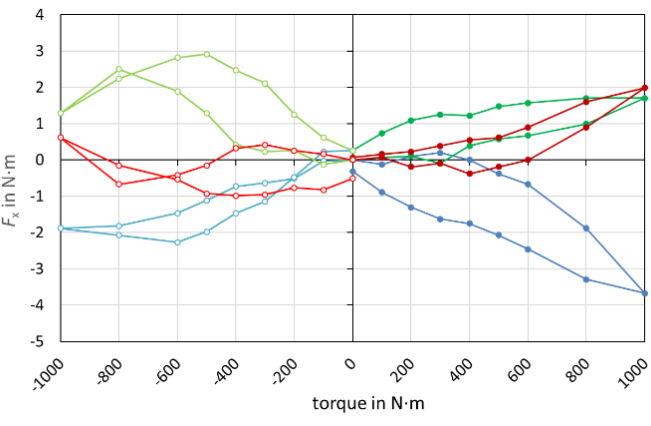

a) $\rightarrow \mathrm{C} 0^{\circ} \rightarrow \mathrm{C} 120^{\circ} \rightarrow \mathrm{C} 240^{\circ} \rightarrow \mathrm{AC} 0^{\circ} \rightarrow \mathrm{AC} 120^{\circ} \rightarrow \mathrm{AC} 240^{\circ}$

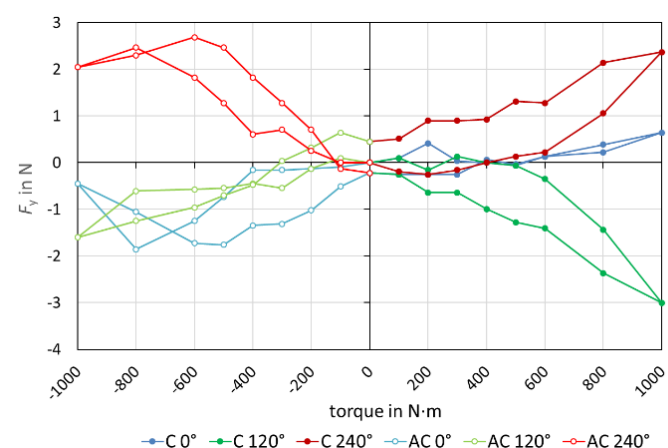

b) $\rightarrow \mathrm{C} 0^{\circ} \rightarrow \mathrm{C} 120^{\circ} \rightarrow \mathrm{C} 240^{\circ} \rightarrow \mathrm{AC} 0^{\circ} \rightarrow \mathrm{AC} 120^{\circ} \rightarrow \mathrm{AC} 240^{\circ}$

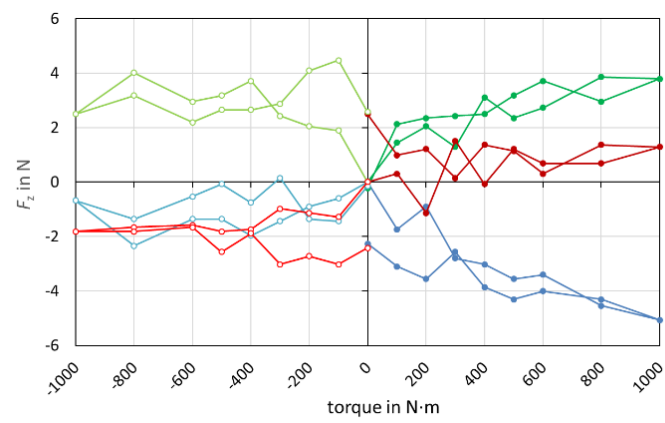

c) $\rightarrow \mathrm{C} 0^{\circ} \rightarrow \mathrm{C} 120^{\circ} \rightarrow \mathrm{C} 240^{\circ} \rightarrow \mathrm{AC} 0^{\circ} \rightarrow \mathrm{AC} 120^{\circ} \rightarrow \mathrm{AC} 240^{\circ}$

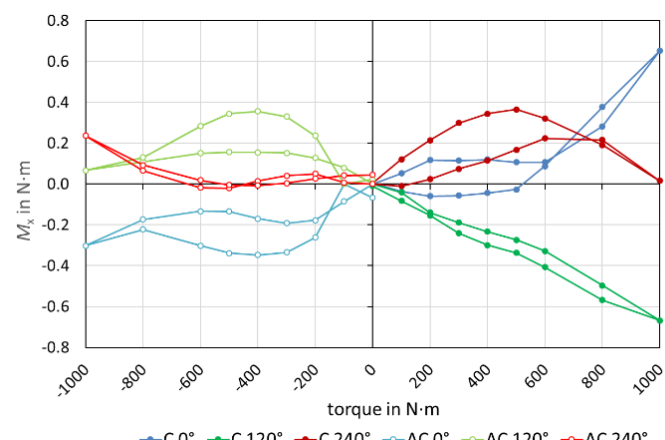

d)

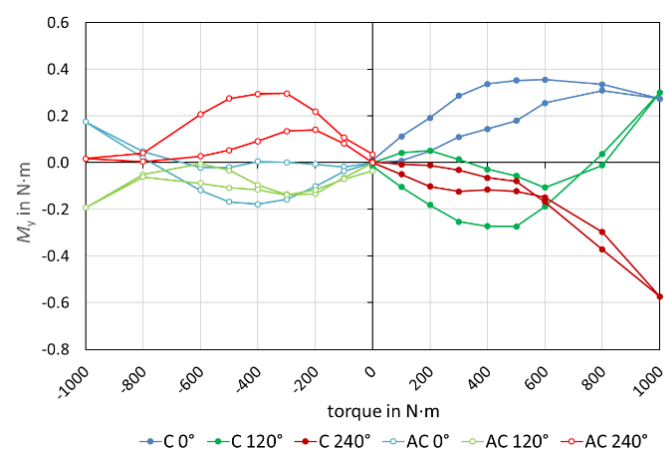

Figure 16. Parasitic loads of the $1 \mathrm{kN} \cdot \mathrm{m}$ TSM at CMI estimated using the PTB MCTT. 
Table 8. Acting parasitic loads (in $\mathrm{N}$ or $\mathrm{N} \cdot \mathrm{m}$ ) relative to the maximum applied torque $(2 \mathrm{kN} \cdot \mathrm{m}$ or $1 \mathrm{kN} \cdot \mathrm{m})$ of the corresponding TSM.

\begin{tabular}{ccccc}
\hline & $\begin{array}{c}\text { PTB } \\
20 \mathrm{kN} \cdot \mathrm{m} *\end{array}$ & $\begin{array}{c}\mathrm{PTB} \\
1 \mathrm{kN} \cdot \mathrm{m}\end{array}$ & $\begin{array}{c}\mathrm{VTT} \\
2 \mathrm{kN} \cdot \mathrm{m}\end{array}$ & $\begin{array}{c}\mathrm{CMI} \\
1 \mathrm{kN} \cdot \mathrm{m}\end{array}$ \\
\hline$F_{x / y}$ & $0.23 \%$ & $0.34 \%$ & $0.85 \%$ & $0.34 \%$ \\
$F_{z}$ & $0.15 \%$ & $0.25 \%$ & $0.20 \%$ & $0.50 \%$ \\
$M_{x / y}$ & $0.12 \%$ & $0.17 \%$ & $0.09 \%$ & $0.11 \%$ \\
\hline
\end{tabular}

* Measured up to $2 \mathrm{kN} \cdot \mathrm{m}$.

indicator for the experimenter when side loads are not negligible. Below, we propose an easy-to-apply system of three categories.

Category 1 contains results with an influence of less than $0.1 \%$, which can most likely be neglected.

Category 2 contains results with an influence between $0.1 \%$ and $1 \%$. Parasitic loads in this order of magnitude can influence the torque calibration (in particular, the signal of a sensitive torque or multi-component torque transducer). For MCTTs, it should be noted that the signal crosstalk behaviour is a combination of crosstalk according to the applied torque and the parasitic loads.

Category 3 contains results above $1 \%$. Values in this order of magnitude indicate significant misalignment or other influences in the TSM; here, a detailed analysis of causes should be carried out. Furthermore, the calibration results must be critically examined.

This scheme should be further investigated theoretically as well as in practical applications.

\section{CONCLUSION}

In this work, an analytical, numerical, and metrological analysis of the sensitivity matrix of two multi-component torque transducers was carried out. In a comparison measurement, the order of magnitude of acting parasitic loads in the TSMs of the participating NMIs was estimated. The values of side loads during a torque calibration are normally not equal to zero and should be determined. We proposed an easy-to-use system with three categories to evaluate the relative magnitude of acting parasitic loads on torque calibrations. To improve the comparability and traceability of the influence of parasitic loads on torque calibrations, it would be desirable for more NMIs to carry out such investigations on their TSMs.

\section{ACKNOWLEDGEMENTS}

Part of this work has been carried out as part of the European Metrology Programme for Innovation and Research (EMPIR). The EMPIR initiative is co-funded by the European Union's Horizon 2020 research and innovation programme and the EMPIR Participating States.

The authors would like to thank the EU and the countries participating in the EMPIR programme for their support and funding.

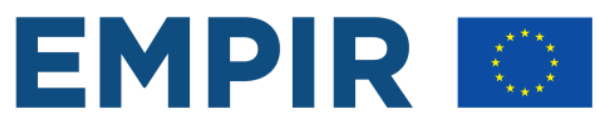

EURAMET

The EMPIR initiative is co-funded by the European Union's Horizon 2020 research and innovation programme and the EMPIR Participating States

\section{REFERENCES}

[1] P. Averlant, P. Lacipiere, J.-M. David, Development of the new LNE $5 \mathrm{kN} \cdot \mathrm{m}$ deadweight torque standard machine, Proc. of the IMEKO 22 $2^{\text {nd }} \mathrm{TC} 3,12^{\text {th }}$ TC5 and $3^{\text {rd }}$ TC22 International Conferences, Cape Town, South Africa, 3 - 6 February 2014. Online [Accessed 20190912]:

https://www.imeko.org/publications/tc3-2014/IMEKO-TC32014-001.pdf

[2] H. J. Fraiss, L. Stenner, D. Röske, Development of a new 400 $\mathrm{kN} \cdot \mathrm{m}$ torque calibration machine, Proc. of the XXI IMEKO World Congress, Measurement in Research and Industry, Prague, Czech Republic, 30 August - 4 September 2015. Online [Accessed 20190912]: https://www.imeko.org/publications/wc-2015/IMEKO-WC2015-TC3-039.pdf

[3] T. Li, H. Qi, X. Ni, Y. Chen, Y. Wang, The realization of micro torque calibration and measurement device, Proc. of the IMEKO $2^{\text {rd }}$ TC3, $13^{\text {th }}$ TC5 and $4^{\text {th }}$ TC22 International Conference, Helsinki, Finland, 30 May-1 June 2017. Online [Accessed 20190912]: https://www.imeko.org/publications/tc3-2017/IMEKO-TC32017-013.pdf

[4] J. Torres-Guzman, J. Galvan Mancilla, Torque metrology in Mexico, twenty years, Proc. of the XXI IMEKO World Congress, Measurement in Research and Industry, Prague, Czech Republic, 30 August - 4 September 2015. Online [Accessed 20190912]: https://www.imeko.org/publications/wc-2015/IMEKO-WC2015-TC3-084.pdf

[5] N. Medina, J. L. Robles, J. A. Trujillo, J. A. Robles Carbonell, Enlargement of the torque measurement capabilities at CEM: development of a $10 \mathrm{kN} \cdot \mathrm{m}$ deadweight torque standard machine, Proc. of the IMEKO 22 $2^{\text {nd }}$ TC3, $12^{\text {th }}$ TC5 and $3^{\text {rd }}$ TC22 International Conferences, Cape Town, South Africa, 3-6 February 2014. Online [Accessed 20190912]:

https://www.imeko.org/publications/tc3-2014/IMEKO-TC32014-012.pdf

[6] M. Woźniak, D. Röske, Investigation of the calibration and measurement capabilities of the new $5 \mathrm{kN} \cdot \mathrm{m}$ torque calibration machine at GUM, Proc. of the XXI IMEKO World Congress, Measurement in Research and Industry, Prague, Czech Republic, 30 August - 4 September 2015. Online [Accessed 20190912]: https://www.imeko.org/publications/wc-2015/IMEKO-WC2015-TC3-092.pdf

[7] Z. Zhimin, Z. Yue, M. Feng, J. Jile, H. Gang, Z. Wei, Establishment of $20 \mathrm{kN} \cdot \mathrm{m}$ torque standard machine at NIM, Proc. of the IMEKO $23^{\text {td }}$ TC3, $13^{\text {th }}$ TC5 and $4^{\text {th }}$ TC22 International Conference, Helsinki, Finland, 30 May - 1 June 2017. Online [Accessed 20190912]: https://www.imeko.org/publications/tc3-2017/IMEKO-TC32017-026.pdf

[8] EURAMET cg-14, Guidelines on the Calibration of Static Torque Measurement Devices, EURAMET, 2011.

[9] D. Peschel, Mechanical Parasitic Components and Their Influence on the Calibration of Torque Transducer, Proc. of the $13^{\text {th }}$ IMEKO TC3 Conference, Helsinki, Finland, 10 - 14 May 1993.

[10] A. Brüge, D. Peschel, D. Röske, 'The Influence of Misalignment on Torque Transducers', Proc. of the XVI IMEKO World Congress, Vienna, Austria, 25 - 28 September 2000. Online [Accessed 20190912]: https://www.imeko.org/publications/wc-2000/IMEKO-WC2000-TC3-P061.pdf

[11] D. Röske, Zum Einfluss mechanischer Störkomponenten auf die Messung von Drehmomenten mit DMS-Aufnehmern, Braunschweig: Physikalisch-Technische Bundesanstalt, 1999 [in German].

[12] EMPIR project 14IND14, Torque Measurement in the $\mathrm{MN} \cdot \mathrm{m}$ Range, EURAMET. Online [Accessed 20190912]: https://www.ptb.de/emrp/torquemetrology.html 
[13] M. Dietrich, Development of torque transfer standards allowing the influence of parasitic forces and moments to be compensated and the disturbing quantities to be measured, Atti del XXI Convegno Nazionale AIAS, Genoa, Italy, 1992.

[14] K. Adolf, D. Mauersberger, D. Peschel, Specification and uncertainty of measurements of the PTB's $1 \mathrm{kN} \cdot \mathrm{m}$ torque standard machine, Proc. of the $14^{\text {th }}$ IMEKO TC3 Conference, Warsaw, Poland, 11 - 14 September 1995.

[15] D. Peschel, K. Adolf, Projekt einer 20-kN·m-DrehmomentNormalmeßeinrichtung, PTB-Mitteilungen, Braunschweig, 1991, [in German].
[16] Y. Park, R. Kumme, D. Röske, D. Kang, Evaluation of multicomponent force transducers having column type sensing element, Proc. of the XIX IMEKO World Congress, Lisbon, Portugal, 6 - 11 September 2009. Online [Accessed 20190912]: https://www.imeko.org/publications/wc-2009/IMEKO-WC2009-TC3-157.pdf

[17] K. Hoffmann, Eine Einführung in die Technik des Messens mit Dehnungsmessstreifen, Hottinger Baldwin Messtechnik GmbH, Darmstadt, 1987 [in German]. 